Modern Asian Studies 53, 3 (2019) pp. 755-775. (C) Cambridge University Press 2019. This is an Open Access article, distributed under the terms of the Creative Commons Attribution licence (http://creativecommons.org/licenses/by/4.o/), which permits unrestricted re-use, distribution, and reproduction in any medium, provided the original work is properly cited.

doi:10.1017/Soo26749X18000495

\title{
Marginal Hubs: On conviviality beyond the urban in Asia: Introduction*
}

\section{MAGNUS MARSDEN}

\author{
University of Sussex \\ Email:m.marsden@sussex.ac.uk
}

\author{
MADELEINE REEVES \\ University of Manchester \\ Email:madeleine.reeves@manchester.ac.uk
}

\begin{abstract}
This special issue explores the forms of coexistence that emerge in what we call 'marginal hubs': sites that appear geographically or politically marginal, but which emerge as areas of intense and often volatile sociability, including border posts, container markets, industrial workshops, and pilgrim encampments. Such sites, which often come into being suddenly and are remote from the great urban centres, do not fit easily either within the framework of the Asian urban nor of the continent's villages and small towns. By exploring the forms of sociability that are important to everyday life in such places, we seek to widen the spectrum

* Magnus Marsden wishes to acknowledge support from the European Research Council (ERC) under the European Union's Horizon 2020 research and innovation programme 669 132-TRODITIES, 'Yiwu Trust, Global Traders and Commodities in a Chinese International City'. Madeleine Reeves wishes to acknowledge support from the Wenner Gren Foundation for Anthropological Research under the International Collaborative Research Grant, 'Conviviality and Contention in Southern Kyrgyzstan: An Infrastructural Approach'. Both of us would like to thank the organizers of the 'InterAsian Connections V' conference held in Seoul in April 2016 and acknowledge funding from the Social Science Research Council (SSRG) without which it would have been impossible to hold the workshop that led to this collection of articles. We are indebted to the participants and discussants in the 'Marginal Hubs' workshop for their participation.
\end{abstract}


of settings that are recognized by scholars across the humanities and social sciences as having the potential to offer productive insights into understanding how heterogeneity is handled in Asia and beyond. This Introduction sets out the theoretical stakes of such an approach, as well as introducing the articles in this special issue.

\section{Introduction}

Recent work in anthropology, history, and related disciplines has cast much light on the varying ways in which people living in Asia's great urban centres have forged collective forms of life across multiple boundaries, including those of religion, ethnicity, language, profession, and class. Studies of paradigmatic urban centres across the continent-ranging from Bukhara ${ }^{1}$ and Istanbul $^{2}$ to Bombay/Mumbai ${ }^{3}$ and $\mathrm{Karachi}^{4}$ —have addressed the ways in which the authorities and inhabitants of such cities have handled, with varying degrees of success, social heterogeneity. There has also been growing recognition of the dangers of romanticizing or overexaggerating the innate capacity of such great urban centres to contain the pressures and strains associated with social heterogeneity. A variety of recent studies, rather, have drawn attention to the ways in which conflict and violence-often played out in the language of (or at least represented as being about) collective forms of identity-are an integral, if not defining, feature of Asia's urban centres. ${ }^{5}$ They have also explored how the very language of urban 'cosmopolitanism' can be invoked by those 'looking to assert or assume the mantle of power' to exclude others from political life. ${ }^{6}$ Parallel to the emergence of this body of work on the Asian city as a site of diversity, scholars working

${ }^{1}$ C. Humphrey, M. Marsden and V. Skvirskaja, 'Cosmopolitanism and the City: Interaction and Coexistence in Bukhara', in The Other Global City, (ed.) S. Mayaram (New York: Routledge, 2008), pp. 202-232.

${ }^{2}$ L. Can, 'Connecting People: A Central Asian Sufi Network in Turn-of-the-Century Istanbul', Modern Asian Studies vol. 46, no. 2, 201 2, pp. 373-401.

${ }^{3}$ N. Green, Bombay Islam: The Religious Economy of the West Indian Ocean, I840I915 (Cambridge: Cambridge University Press, 2012); G. Prakash, Mumbai Fables (Princeton: Princeton University Press, 2010).

${ }^{4}$ L. Ring, Zenana: Everyday Peace in a Karachi Apartment Building (Bloomington: Indiana University Press, 2008).

${ }^{5}$ N. Green, 'The Demographics of Dystopia: The Muslim City in Asia's Future', History and Anthropology vol. 27, no. 3, 2016, pp. 273-295; L. Gayer, Ordered Disorder and the Struggle for the City (London: Hurst, 2014).

${ }^{6}$ B. Grant, 'Cosmopolitan Baku', Ethnos vol. 75, no. 2, 2010, p. 125. 
in rural settings have sought to challenge the conventional notion that villages and small towns are inevitably homogeneous or devoid of social heterogeneity. ${ }^{7}$ Such studies have brought into focus the forms of circulation and migration that are a critical feature of village life in many parts of Asia. They have also highlighted the nuanced sensibilities that rural people demonstrate in the ways in which they handle, think about, and engage with the forms of diversity that arise from such circulations. ${ }^{8}$

The contributors to this special issue build on these important bodies of literature, yet do so on the basis of empirical material relating to the experience of everyday life in contexts that do not fit easily either within the framework of the Asian urban nor of the continent's villages and 'small towns'. ${ }^{9}$ The type of settings through which the articles explore questions of how people from very different backgrounds seek to live side-by-side (if not always in an inconclusively sociable way) include border posts, sprawling markets on the urban periphery of mega-cities, 'villages in the city' that are home to industrial workshops, and pilgrim encampments located in the mountain wilderness. A central aim for this collection of articles is to document and theorize the forms of sociality that are important within such settings.

In order to do so, we advance two central theses that run through the case studies in this collection. First, the backdrop to these case studies are sites that straddle the often taken-for-granted boundary between the rural and the urban, the modern and the historic, the marginal and the central. We suggest that such sites represent a specific type of setting: the 'marginal hub'. By exploring the forms of sociability that are important to everyday life in such marginal hubs, we hope to widen the spectrum of settings that are recognized by scholars across the humanities and social sciences as having the potential to offer productive insights into understanding how heterogeneity is handled

${ }^{7}$ L. Heslop, 'The Making of the Merchant Middle Class in Sri Lanka: An Ethnography of Small Town Life', PhD thesis, University of Edinburgh, 2015; M. Marsden, 'Muslim Cosmopolitans?: Transnational Life in Northern Pakistan', The Journal of Asian Studies vol 67, no. 1. 2008, pp. 213-248.

${ }^{8}$ V. Gidwani and K. Sivaramakrishnan, 'Circular Migration and Rural Cosmopolitanism in India', Contributions to Indian Sociology vol. 37, no. 1-2, 2003, pp. 339-367; M. Saxer, 'Pathways: A Concept, Field Site, and Methodological Approach to Study Remoteness and Connectivity', Himalaya vol. 36, no. 2, 2016, pp. 105-1 19.

${ }^{9}$ On the notion of the Asian urban, see P. van der Veer, 'The Future of Utopia', History and Anthropology vol. 27, no. 3, 2016, pp. 251-261. 
in Asia and beyond. Second, we have found the concept of 'conviviality' especially helpful in understanding the complex forms of sociability on display in the marginal hubs on which the articles focus. As the articles collected in this special issue document, the social dynamics of marginal hubs should be conceived of neither in terms of breakdown and dystopia, nor as utopian forms of sweetly reasonable coexistence. Thinking through the social dynamics of such sites in terms of conviviality shifts attention away from strivings for cosmopolitanism or toleration and coexistence, and towards the intrinsic ambivalence of living together across local differences, which are themselves often inflected with the dynamics of power and exclusion, or what Emily Yeh felicitously calls 'coercive amity'. ${ }^{10}$ What emerges especially clearly from a consideration of the pervasive ambivalence of such 'livingwith' is that it is necessarily full of frictions and misunderstandings. ${ }^{11}$ Empirical explorations of such settings stand well placed to provide the basis for original and critical perspectives on conviviality's value as an analytical device for understanding the modes through which diversity is handled and conceptualized in particular settings and on a day-to-day basis.

The two tropes that we have introduced here-the 'marginal hub' and 'conviviality beyond the urban centre'-weave in and out of the various articles that make up this collection. These terms served as organizing devices for the workshop, part of the 2016 SSRC InterAsian Connections V' conference held in Seoul, at which these articles were initially presented, and we have returned to them repeatedly in discussions within and beyond the workshop. Some of the articles in this collection foreground one or the other of the two terms; others explore the relationship between the two more symmetrically. We have sought not to be prescriptive in how authors engage with the terms across divergent settings and bodies of empirical material. Our hope, nonetheless, is that collectively the articles published here provide new theoretical and empirical insights into the everyday work of living together in Asia beyond the region's great urban centres.

10 E. Yeh, 'Living Together in Lhasa: Ethnic Relations, Coercive Amity and Subaltern Cosmopolitanism', in The Other Global City, (ed.) Mayaram, pp. 54-85; Cf. R. Chandavarkar, History, Culture and the Indian City (New York: Cambridge University Press, 2009); M. Liu, Under Solomon's Throne: Uzbek Visions of Renewal in Osh (Pittsburgh: University of Pittsburgh Press, 2012 ).

${ }^{11}$ H. Al-Mohammad, 'Towards an Ethics of Being-With: Intertwinements of Life in Post-Invasion Basra', Ethnos vol. 75, no. 4, 2010, pp. 425-446. 
We proceed by elaborating on the implications of this approach for two broad scholarly conversations concerning, on the one hand, the specificity of the urban as a site of social interaction in Asia and, on the other, the value of conviviality as an analytic for exploring dynamics of coexistence. After situating our approach in critical conversation with these broader debates, we outline more specifically what such an approach to everyday conviviality in marginal hubs might look like. We draw out four dimensions of the enactment of conviviality in marginal hubs that we regard as especially important-ephemerality, materiality, volatility, and historicity - and elaborate on each through a discussion of individual articles in the collection.

\section{Approaching conviviality beyond the urban centre}

One especially salient aspect of the marginal hub as a site of social interaction is the extent to which such settings often emerge not from longue durée histories but in the context of far more abrupt, and often short-lived, historical developments. If work on Asia's paradigmatic urban centres tends to focus on the modes of living together that have been worked out by diverse communities over decades or centuries of shared residence and interaction, then the type of setting on which the articles in this volume focus are frequently the product of short-term historical processes that abruptly throw together people from very different backgrounds with few, if any, visible histories of past interaction. The inhabitants of urban neighbourhoods typically witness successive waves of incomers from contrasting regions and socio-economic backgrounds, and each wave leaves behind social infrastructures that may be adopted, adapted, or violently appropriated by future generations of migrants, sojourners, or exiles. ${ }^{12}$ Marginal hubs, by contrast, emerge sporadically and often suddenly. They bring together people with little in the way of a history of collective interaction. Given that their existence is closely tied up with rapidly changing political and economic dynamics, marginal hubs fulfil few of the criteria that would help to forecast the prospect of future social stability.

Studying the everyday social dynamics that are found in such marginal hubs raises important questions about conviviality. The

${ }^{12}$ For example, J. Sahadeo, Russian Colonial Society in Tashkent, I865-1923 (Bloomington: Indiana University Press, 2007); J. Nucho, Everyday Sectarianism in Urban Lebanon: Infrastructures, Public Services and Power (Princeton: Princeton University Press, 2016). 
almost exclusive focus in the existing literature on social heterogeneity on 'the urban' as a backdrop for everyday forms of conviviality has produced detailed empirical and analytical discussions of the practices that enable people to fashion relations and lives across boundaries and divides. ${ }^{13}$ Yet there remains a lingering assumption in some scholarship that it is the urban itself that provides people with the cultural, social, and affective resources to learn, embody, and deploy such practices. ${ }^{14}$ Against this intellectual backdrop, scholarly recognition of the importance of conviviality to living with difference in a wider range of settings has the potential to raise new questions concerning the historical and cultural sources of convivial practices, sensibilities, and knowledges. On what resources do people in marginal hubs draw in their attempts to forge social ties and relations across boundaries of difference, or to categorize and define one another? How are social bonds and ties fashioned in the apparent absence of past histories, stories, and memories of collective social life?

The articles in this special issue all attend to the broader processes of politics and economy that are critical to understanding the emergence and dynamics of such sites. Marginal hubs do not emerge from thin air. Rather, as the articles in this collection illuminate, they are connected to identifiable processes, including the globalization of the world's supply chains, the securitization of boundaries between nationstates, and the politicization of ethnic and religious differences. Such processes are rarely associated with the emergence of harmonious forms of collective living or, indeed, of the type of social contexts in which such modes of life take root. Be it in the need for a motivated labour force or for unambiguous divisions of loyalty and territory at contested national boundaries, marginal hubs are integrally connected to wider, and often exploitative and violent, processes that are shot through with multiple and overlapping forms of inequality. How such processes come to be ignored, acknowledged, diffused, or jokingly reworked in everyday encounters are questions deserving of finegrained, ethnographic attention.

\footnotetext{
${ }^{13}$ For example, C. Humphrey and V. Skvirskaja (eds), Explorations of the PostCosmopolitan City (New York and Oxford: Berghahn Books, 2012); Marayam (ed.), The Other Global City; N. Carrier, Little Mogadishu: Eastleigh, Nairobi's Global Somali Hub (London: Hurst and Co., 2016).

${ }^{14}$ For example, A. Amin, 'Land of Strangers', Identities: Global Studies in Culture and Power vol. 20, no. 1, 2013, pp. 1-8.
} 


\section{Actually existing coexistence}

The decidedly empirical perspective on conviviality that we pursue here as the effortful labour of actually existing coexistence sits in sympathetic but critical conversation with a growing scholarly literature on cosmopolitanism and what has sometimes been glossed as a 'cosmopolitan vision'. ${ }^{15}$ Cosmopolitanism has been characterized by advocates and critics alike as defined by forms of orientation or attitude in which difference is unmarked, unnoticed, and irrelevant to the texture of daily life. The cosmopolitan subject enjoys the forms of freedom and mutual recognition that flourish in contemporary urban life; they experience difference as enriching rather than threatening, such that 'openness' itself becomes a mark of distinction or mutual identification. Cosmopolitanism in this sense is defined both by an attitudinal or affective component-it emphasizes an orientation, a way of being and relating that is marked by openness and respect, by tolerance and recognition-and by a kind of 'world recognition': the capacity to relate to, or apprehend, the world — the 'cosmo-' - as a singularity. It is in this respect that most Western genealogies of cosmopolitanism trace the term beyond Kant to Diogenes (412-323 BCE), who responded to the question of where he was from by asserting, 'I am a citizen of the world' (kosmopolitês).

In this tradition, cosmopolitan literature has enquired into the contemporary global conditions within which, as Paul Gilroy puts it, 'exposure to otherness involves more than jeopardy'. ${ }^{16}$ And if the freedom to be 'open to the world' often appears as an elite privilegethe perspective, in Craig Calhoun's sharp formulation, of the frequent traveller moving effortlessly between airport lounges ${ }^{17}$ — much recent scholarship has illuminated the cosmopolitanism of those with limited political and material resources for international travel. ${ }^{18}$ Indeed, it is notable in the anthropological and historical scholarship on Asia

\footnotetext{
${ }^{15}$ U. Beck, The Cosmopolitan Vision, (trans) Ciaran Cronin (Cambridge: Polity Press, 2006).

${ }^{16}$ P. Gilroy, 'Beyond Assimilation: Highland Shortbread and the Politics of Belonging in Britain', Heritage and Identity, Heritage Lottery Fund, 2004.

${ }^{17}$ C. Calhoun, 'The Class Consciousness of Frequent Travelers: Toward a Critique of Actually Existing Cosmopolitanism', The South Atlantic Quarterly vol. 101, no. 4, 2002, pp. 869-897.

${ }^{18}$ For example, U. Kothari, 'Global Peddlers and Local Networks: Migrant Cosmopolitans', Environment and Planning D: Society and Space vol. 26, no. 3, 20o8, pp. $5^{00}-5^{16}$.
} 
how often depictions of cosmopolitanism are qualified or hyphenated as discrepant, subaltern, or vernacular. There are accounts of Muslim cosmopolitanism ${ }^{19}$ and Buddhist cosmopolitanism, ${ }^{20}$ just as there are of black cosmopolitanism, ${ }^{21}$ working class cosmopolitanism, ${ }^{22}$ and youth cosmopolitanism. ${ }^{23}$ Openness to difference, such literature suggests, is itself a situated, localized, and learned capacity. It is nurtured in some contexts more than in others. It is precisely in conditions of subordination or inequality that one may not be able to afford not to be 'open to difference'.

Such insights do important work in moving cosmopolitanism from the realm of normative statements into empirical enquiry. They have helped shed 'cosmopolitan theory' of some of its elitist and Eurocentric biases. And they have pointed to the ways in which the identification of others as insufficiently cosmopolitan or insufficiently open can be used to support and reproduce relations of inequality. ${ }^{24}$ The articles in this collection build sympathetically on these insights and critiques. Yet we also take as our starting point the idea that the 'embedded contradictions' of cosmopolitanism require something other than its repeated qualification of hyphenation. The claim of an 'openness to difference', we suggest, implies a perceiving ('open') human subject who is not always-already constituted by relations of power, full of ambivalences, full of contradictory orientations, for

${ }^{19}$ P. Werbner, 'Vernacular Cosmopolitanism as an Ethical Disposition: Sufi Networks, Hospitality and Translocal Inclusivity', in Islamic Studies in the Twenty-First Century, (eds) L. Baskins and A. van Sandwijk (Amsterdam: Amsterdam University Press, 2016), pp. 223-240; M. Marsden, 'Islamic Cosmopolitanism out of Muslim Asia: Hindu-Muslim Business Co-operation between Odessa and Yiwu', History and Anthropology vol, 29, no. 1, 2017, pp. 121-139; R. M. Feener and J. Gedacht (eds), Challenging Cosmopolitanism: Coercion, Mobility and Displacement in Islamic Asia (Edinburgh: Edinburgh University Press, 2018).

${ }^{20}$ K. D. Bhutia, 'Local Agency in Global Movements: Negotiating Forms of Buddhist Cosmopolitanism in the Young Men's Buddhist Associations of Darjeeling and Kalimpong', Transcultural Studies vol. 2016, no. 1, pp. 121-148.

${ }^{21}$ I. K. Nwankwo, Black Cosmopolitanism: Racial Consciousness and Transnational Identity in the Nineteenth-Century Americas (Philadelphia: Pennsylvania University Press, 2005).

${ }^{22}$ P. Werbner, 'Global Pathways: Working Class Cosmopolitans and the Creation of Transnational Ethnic Worlds', Social Anthropology vol. 7, no. 1, 1999, pp. 17-37.

${ }^{23}$ S. Scheld, 'Youth Cosmopolitanism: Clothing, the City, and Globalization in Dakar, Senegal', City and Society vol. 1, no. 2, 2007, pp. 232-253.

${ }^{24}$ N. Glick Schiller and A. Irving, 'Introduction: What's in a Word? What's in a Question?', in Whose Cosmopolitanism? Critical Perspectives, Relationalities and Discontents, (eds) N. Glick Schiller and A. Irving (Oxford and New York: Berghahn, 2014), pp. 1-22. 
whom the embrace and fear of 'difference' may be less polar opposites than two sides of the same coin. ${ }^{25}$ Moreover, it implies that such attitudes and feelings are legible, transparent, and durable: that they are not subject to the vagaries of political events, public discourses, and moral panics.

Our focus on conviviality shifts attention from normative aspirations to the intrinsic ambivalence of living together across local difference, recognizing that such living-with is necessarily full of frictions and misunderstandings. Such an approach draws attention to the temporal and spatial specificity of such practice: the fact that convivial relations can fizzle or snap (see Nikolotov's article in this volume) or that they can be bound by the layered geographies of sociality (see Mostowlansky's article this volume). In this respect, rather than assuming that marginal hubs are best thought of as being the site of urban conviviality's 'other', we suggest, conversely, that a consideration of everyday modes of dealing with diversity within such settings can illuminate not only the practices of conviviality deployed in marginal hubs but also the ways in which people think about and conceptualize these. This is because the people who inhabit, govern, and move through marginal hubs are attuned to the forms of diversity that characterize their worlds, and are often necessarily reflexive about their modes of engaging with these. In this sense, recognizing the 'performed' or strategic elements of conviviality (see Chambers' article in this volume) should not lead us to assume that such relations are therefore either inauthentic or narrowly self-serving. ${ }^{26}$ They reflect instead the intrinsic complexity of a concept that is both analytical and normative: a way of examining social relations that is also a moral model for society that is worth striving for.

This ambivalence also points to the open-endedness and volatility of convivial relations. We do not presume that such co-figuring is necessarily easy, comfortable, or premised upon an 'openness to the

${ }^{25}$ S. Schielke, Egypt in the Future Tense: Hope, Frustration, and Ambivalence before and after 201 I (Bloomington: Indiana University Press, 2015); J. Stacey, 'Whose Cosmopolitanism? The Violence of Idealization and the Ambivalence of Self', in Whose Cosmopolitanism?, (eds) Glick Schiller and Irving, Chapter 4 .

${ }^{26}$ We build here on an extensive body of literature that records the sentiments and interest as co-produced in everyday human life. See, for example, A. Silver, 'Friendship in Commercial Society: Eighteenth-Century Social Theory and Modern Sociology', American Journal of Sociology vol. 95, no. 6, 1990, pp. 14741504 . 
world'. Conviviality entails, rather, forms of everyday practices that have uncertain trajectories: a misplaced joke might lead to spiralling violence or, if interpreted and received through different registers, to the emergence of social relations that are characterized by peace and harmony. Because they bring together people in the context of testing times and across vexed spaces, marginal hubs provide a tangible context within which to explore the multiple and unfolding trajectories of convivial modes of living together. We turn now to exploring these dimensions of the marginal hub in more depth, through reference to the individual articles in the collection.

\section{Ephemerality}

As we have noted above, marginal hubs often arise from abrupt and shifting historical processes: the search for new markets, new resources, new supply chains, or new security imperatives. As such, specific attention also needs to be paid to the ephemeral nature of conviviality in such settings. Much work on cosmopolitanism emphasizes the importance of durable spaces, cultural traditions, and institutions in maintaining carefully balanced patterns of relations between different groups in society. By contrast, the articles in this volume point to the importance of ways of speaking and behaving that are far less securely moored in the social fabric or cultural traditions of marginal hubs. Convivial practices that are inherently ephemeral include specific types of social interaction, such as jokes, banter, or off-hand remarks. How do we assess the role that such hard-to-trace forms of social interaction play in peoples' attempts to live with one another? Do certain types of practice (such the sharing of food or tools or workspace) inevitably result in convivial relations? Alternatively, might practices that are convivial bring differences, divisions, and distinctions to participants' attention, even as they make possible sociability across various boundaries? ${ }^{27}$ Under what circumstances does attention to social difference-ranging from committed social investment at one end of the spectrum to irony and cynicism at the other-result in the production of the dynamic and intensive types of sociality that we are referring to as conviviality?

\footnotetext{
${ }^{27}$ Anthropologists have long recognized the power of hospitality to divide as much as unite guests and hosts. See, for example, Charles Lindholm, Generosity and Jealousy: The Swat Pukhtun of Northern Pakistan (New York: Columbia University Press, 1983).
} 
Thomas Chambers addresses these issues with especial clarity in the context of Saharanpur, a Muslim-majority neighbourhood in Uttar Pradesh, northwest India. Saharanpur is a 'provincial urban centre': a type of setting which, in comparison to both the subcontinent's villages and its mega-cities, has received comparatively little attention in regional and comparative scholarship. The city is widely recognized by its inhabitants as one that is welcoming to outsiders, not least because of the way in which it absorbed Muslim refugees in the context of the violent events of partition in 1947. It would be wrong to characterize Saharanpur as harmonious in any simple way, however: the city's Muslim, Sikh, and Hindu communities live rather segregated lives and there have also been violent confrontations-coded as 'religious'—in recent years. Within Saharanpur Chambers' focus is on a particularly important unit of sociality within and beyond South Asia: the mohalla, or neighbourhood. In Saharanpur, neighbourhoods are critical to the organizations of the city's economy: the craft industry, most especially the production of goods from wood, which are often also sold and distributed globally. In his article Chambers suggests that mohallas 'ferment... intense forms of sociality', which we might think of in terms of 'conviviality'. He suggests, however, that it would be an oversimplification to understand such convivial modes of being simply in terms of the fashioning of harmonious intra-communal relations, even though many of the cases he explores involve ties and friendships that stretch across communal boundaries. Indeed, Chambers argues that there is a powerful duality in such forms of conviviality: they build bridges across boundaries that are not only important to city dwellers' everyday lives, but also contain a degree of instrumentality. For Chambers, such everyday performance of conviviality also reinforces multiple 'obligations' and 'power-laden' reciprocal ties, meaning that it plays a crucial role in the way in which control over labour and production in the city's mohallas is maintained more generally.

In the context of intense migration, industrialization, and urbanization, Nellie Chu's article addresses the complex interplay of personal affect and social control in everyday lives in the Chinese garment industry. Chu pays explicit attention to the important role that marginal hubs play as sites of labour and manufacture in South China. Chu exploresjiagongchang household workshops in Guangzhou's garment district. Such jiagongchang account for as much as 5 per cent of China's production of clothing; they are of critical importance in the ability of suppliers in the city to meet a rapid demand for clothing suitable for export to various corners of the globe, from Thailand to 
Australia. Within Guangzhou, these jiagongchang are situated within chengzhongcun, or 'villages in the city': spaces that are not classified by Chinese legislation as urban but which have become enveloped by Guangzhou's unchecked urbanization. As such, this type of social environment has emerged historically from the 'spatial interstices of rural/urban, home/factory, and state/collective land'. A key theme cutting across Chu's article, indeed, is the way in which workers in jiagongchang-most of whom, in this particular sector of the household economy, are women-manage multiple and ambiguous boundaries in their daily lives.

For Chu, jiagongchang are helpfully conceived of as being 'marginal hubs' because they are 'temporary sites of internal exclusion and dispossession across transnational supply chains, where the offshoring of low-cost manufacturing and the displacement of life and livelihood take place in order to facilitate the just-in-time delivery of lowcost commodities'. In this respect, Chu's work chimes with Thomas Chambers' recognition of the significance of Saharanpur as a site of industrial manufacture: both urban settings are sites in which precarious labour is predominant and also rooted in specific units of sociality: the neighbourhood in Saharanpur and the 'village in the city' in Guangzhou. Yet whereas Chambers sheds light on the intersection between masculinity and sociality to the performance of such forms of labour, in Chu's case household workshops rely on female migrant workers' 'negotiations with their feelings of displacement' and the women's ability to handle the boundary between being 'wage workers and domestic caretakers'. Chu goes beyond the temptation to see unrequited desire for home and family (such a powerful aspect of these women's subjectivities) as a simple issue that needs to be solved by factory owners keen to maintain high levels of productivity. Instead, Chu argues that 'affection for a loved one in a distant place ... becomes a mobilizing force of low-wage labour along an uneven and disjointed chain of marginalized labour and hub of extraction'. In other words, women regard serving simultaneously as their families' 'caretaker and breadwinner' and 'seamstress' as furthering the possibility of leading 'responsible' lives, which they might contrast with the 'wayward' existences of those left behind in their villages.

The capacity of women to seek meaning in their working lives in the household workshops through their identities as mothers and carers is not simply a matter of their personal or collective 'resilience'. Rather, Chu deftly shows the ways in which it is not only legal and 
spatial boundaries that are blurred in the context of Guangzhou's chengzhongcun. Of central significance for the functioning of this mode of production are blurred boundaries in the nature of social relationships between factory owners and workers, as well as between wholesale suppliers and factory owners. In this respect, Chu charts the ways in which the ability of a wholesaler to complete an order in time for a purchaser in Australia is dependent on her ability to muster the affective resources that ensure a factory owner is willing to labour at short notice and for long hours. Chu also provides fascinating glimpses into the ways in which this mode of organizing labour production not only blurs vertical relationships between factory owners and workers but is also manifest in rich relationships of care-giving and solidarity on the workshop floor: relationships which often cut across differences in regional backgrounds. Chu deploys the concept of 'diasporic intimacy' to describe the way in which migrants come together through a 'shared sense of precariousness or alienation in a foreign land, however shortlived this encounter may be'. By treating household workshops as 'temporary sites' that 'serve as fragmented and provisional resources of sociality and labour', while also recognizing the forms of intimacy and care that not only emerge in but are also central to the ongoing economic role of such contexts, Chu's article sheds especially vivid light on the ambiguity of the forms of conviviality that appear to characterize everyday life in Asia's marginal hubs.

\section{Materiality}

Recent attempts to engage critically with the concept of cosmopolitanism from non-elite perspectives have dwelt extensively on the instruments and substances that facilitate openness to difference in specific contexts and settings. From recognition of the importance of the pots in which food is cooked, to the rooms in which guests are hosted, to the recipes used to accommodate different tastes and demonstrate knowledge of difference, anthropologists have challenged Eurocentric approaches to cosmopolitanism as a theory to recognize instead the way in which openness to difference is embodied and materially embedded in everyday life. ${ }^{28}$ Several of the articles in this

${ }^{28}$ F. Osella and C. Osella, "I am Gulf”: The Production of Cosmopolitanism in Kozhikode, Kerala, India', in Struggling with History: Islam and Cosmopolitanism in the Western Indian Ocean, (eds) K. Kresse and E. Simpson (London: Hurst, 2007), pp. 
special issue build on this work by bringing attention to the materiality of the expressions of conviviality evident in the marginal hubs under examination.

An overwhelmingly predominant focus of work on migration and mobility in Asia has been on the multidimensional implications of the resettling of rural communities in the continent's cities. Yasmin Cho's article in this special issue serves as an important reminder that migration to remote areas also exists and that margins do not serve merely as the 'other' of the urban centre, but can come to exert a centralizing pull themselves. Foremost in Cho's approach is a need to recognize the significance of the physical environment and peoples' conceptions of it in shaping understandings of centre and margin. Cho explores the importance of Yachen Gar's 'remoteness and wilderness' to the religious experiences of Buddhist nuns in a Tibetan monastery. This Tibetan Buddhist encampment has arisen since the 1980 s in the Kham region, a space historically 'sandwiched between Central Tibet and China proper' and which has maintained 'its distance from both these powerful political entities ... generating its own sociohistorical trajectories'. It now forms the largest Buddhist community in China, comprising 10,000 nuns as well as 2,000 monks and practising lay people. Most of the devotees based at Yachen Gar hail from the Tibetan Autonomous Region (TAR), but there are growing numbers of Han Chinese pilgrims. The monastery is notoriously difficult to reach: even when roads are constructed, they are quickly washed away by floods and landslides.

Central to Cho's argument is that, while it is conventional to focus on the cosmological position of religious centres in Tibetan Buddhism, the material features of such communities should not be overlooked. Indeed, in the case of Kham, a focus on materiality and geography reveals important dimensions of the monastery's success in attracting followers. Cho focuses on a 'distant centre' in order to contest the notion-visible especially in the Lefebvrian notion of the 'social production of space'- that margins are inevitably produced in a passive or reactive way as a result of the emergence of powerful centres. The case of Yachen Gar, however, reveals the case of a margin that is explicitly sought out and produced by multiple agents and forces. As Cho demonstrates, before the monastery emerged in Yachen Gar, the

323-356; M. Marsden, 'Fatal Embrace: Trading in Hospitality on the Frontiers of South and Central Asia', Journal of the Royal Anthropological Institute vol. 18, no. 1, 2012 , pp. $117-130$ 
setting was thought of a 'nowhere' rather than a margin. It was in the context of active acts of 'distancing' that pilgrims and nuns removed themselves from certain things (their places of origin, polluted urban centres, or modernity itself) and in doing so made possible a new web of social relations, involving nuns, lamas, and Chinese pilgrims. In this respect, Yachen Gar was simultaneously actively constructed as a margin but also as a new type of centre. Cho's findings offer a very different geographical optic for the study of the marginal hub than those of other contributors to this special issue (especially Chambers and $\mathrm{Chu}$ ) who trace the emergence of marginal hubs in urban centres as sites of immigration. As is the case, however, for the Pamiri mountain dwellers explored by Mostowlansky in his article, being remote and isolated has a range of implications for the devotees based at the camp.

Such active forms of 'distancing' have significant yet varied implications for the way in which Yachen Gar is experienced by those who visit its Buddhist community. On the one hand, the practices and activities of nuns in the monastery are regarded as being less intrusively observed by the Chinese authorities than is the case for more historically significant monasteries. On the other hand, being located in a remote wilderness is regarded by the nuns as making possible forms of detachment from the world that are not possible in monasteries that are less remote. The reason for this does not simply arise from the ability of nuns to detach themselves spiritually from the world, although from the perspective of the Han devotees, the remoteness of Yachen Gar intensifies their understanding of the site of the monastery as being especially pure and spiritual. Chinese Han pilgrims indeed expect a certain 'roughness' in Yachen Gar's environment and associate the difficulties in reaching the site with its ability to select those who are suitable to visit. An issue of importance for the nuns from the TAR, however, relates to the significance of monasteries to local economies and social structures. In parts of Tibet in which monasteries are located close to local communities, nuns are 'often bound by seasonal labour obligations'.

Malini Sur's ethnography of another out-of-the-way-place-the India-Bangladesh border in the Garo Hills_-also directs our attention to the materiality of the marginal hub and its affordances (and limitations) for everyday convivial relations. The heavily militarized border region in the Garo Hills, saturated with histories of state violence and asymmetrical relations between villagers and border guards, is today a place renowned for demands for independence, 
indigenous dissidence, smuggling, and trans-border abductions. This would hardly seem an environment conducive to the development of convivial relations. Yet this borderland has also been a site of enduring forms of exchange, albeit asymmetrical and partial, as Sur demonstrates through an ethnography of ritualized exchange between villagers and border forces manifested in the lending and borrowing of fragile porcelain teacups, the use of their jeeps to take critically ill patients to hospital, the sharing of courtyard conversation to diminish the chronic boredom of border patrol, or the requirement to drink tea at the border. The analytical significance of such reciprocal acts is precisely that they take place in a context that is also shot through with inequality: a border-post cup of tea, for instance, might accompany an interrogation. Conviviality does not erase state violence. Indeed, convivial relations are vulnerable to the growing materialisation of border infrastructure as 'sprawling concrete outposts' now dominate the Garo landscape. But little acts of convivial exchange-words, teacups, food-do serve to domesticate borders, making the state 'a familiar neighbourly outpost instead of a distant, violent force' and helping to render life liveable under duress.

\section{Volatility}

Being convivial is not something that comes without sustained effort and social work. As with all forms of effort, conviviality entails expense and expenditure, which take multiple forms. It may be materialized as resources (economic and social) or expended as energy (creative and physical) and embodied in the forms of affects and emotions (both affectionate and hostile). The discussion of conviviality's inherently volatile and ephemeral nature discussed above means that the outcomes of such efforts are never clear; recognition of this in turn raises the stakes and heightens the anticipation of those who invest in everyday acts of conviviality. Indeed, continued and sustained effort itself contributes to the inherently volatile nature of convivial forms of conduct: dealing with difference in fraught settings on a dayto-day basis is intense and often unsettling, with the potential for misunderstanding, miscommunication, and mistranslation never far from the horizon.

Anton Nikolotov's article in this volume explores these themes from the perspective of a sprawling wholesale market in the shadow of the Moscow ring road. Sadovod is a place where thousands of 
traders from South and Central Asia, the Caucasus, Ukraine, and Vietnam figure out the dynamics of co-living and co-trading in an environment segmented by class and racialized hierarchies, shot through with the ever-present risk of scams, violence, and ritualized police raids. Conviviality, in this setting, 'exists within an internal social structure that is far from being a romantic form of interethnic mixing'. It is, rather, a combustible and unpredictable realm in which a 'playful' insult might lead to an invitation to shashlyk or a punch in the face. Making a living in such an environment demands skill-in playful banter with co-traders and prospective buyers, in 'passing' (as Indian rather than Afghan, for instance), in knowing when to flatter and when to diffuse tension with a joke or jibe. It also requires effort. The volatile conviviality of a gathering of traders for shashlyk, for instance, consists not only of threading pieces of meat onto skewers and cooking these over hot charcoal. Instead, as Nikolotov describes, from the preparation and cooking of the meat, to the ability of those gathered to engage in the forms of banter and joking required, the shashlyk gathering requires multiple forms of effort and the ultimate outcome, which might range from somewhere on the spectrum between uproarious laughter and humour to fizzy pop combustibility, is always difficult to predict.

Jacob Nerenberg's article takes us to another market-hub of volatile conviviality: this time in Wamena in the highlands of Indonesia's Papua province. This terminal market in a politically fraught periphery is also a threshold between urban and rural life, and between indigenous and migrant social worlds. Here, as in Sadovod, the market and associated minivan terminal are places of marginal gains for traders who have often exhausted the possibilities for deriving a livelihood from the land. Here, too, the market is a node of tense and often volatile relations across social, religious, and linguistic differences, characterized in the case of Wamena by visibly racialized divisions of labour between indigenous Papuans and migrants from other Indonesian islands. As in Sadovod, these distinctions are not stable or binary. Instead, the market serves as a site for the articulation and amplification of multiple lines of difference and competition according to place of origin and ethnic affiliation.

Nerenberg explores how these tensions can become magnified through fear, rumour, and the (in)action of the Indonesian security forces, transforming convivial relations into potentially violent confrontations, when one or other community is felt to be privileged or undermined by the introduction of new regulations, such as 
the prohibition of Sunday trading. These tensions, he shows, have traceable linkages to the broader inequities of Papua's incorporation into the Indonesian state. The peripherality of Wamena's 'terminal economy', in other words, is not simply a product of geographical remoteness, but is the result of the durable dynamics of colonial incorporation grounded in asymmetrical extraction.

\section{Historicity}

If the marginal hubs explored in this special issue-be they China's 'villages in the city', Russia's container markets, or modern border posts on the Bangladesh-India border-are not sites of historic cosmopolitanism, this does not mean that they are not informed by historical dynamics or, indeed, that those who inhabit them are not historically aware. ${ }^{29}$ Indeed, people in several of the marginal hubs that feature in this special issue actively and imaginatively emplace themselves in relationship to histories of, or paths towards, conviviality. The fraught and violent histories that often lie behind the emergence of marginal hubs do not, of course, unfold in territories that have forever been ungoverned and are merely the dormitories of the world's industrial and military labour force. Marginal hubs, rather, arise from processes that tear centres from their hinterlands and do so in a manner that has long-term consequences for both. As Cho's article demonstrates, peripheries might be actively made as people choose to vacate historic cores for emergent yet marginal centres. The individuals and communities drawn to marginal hubs in the wake of such diverse processes carry with them their own modes of engaging with difference. In some contexts, such histories of conviviality might be directly and consciously connected to historical narratives that depict that marginalization and exclusion of regions and contexts from once convivially connected worlds.

Till Mostowlansky's article addresses the historicity of the forms of conviviality found in marginal hubs by focusing on the 'possibility of shared lives' in the Pamirs, a region that cuts across the boundaries of Tajikistan, Pakistan, China, and Afghanistan. In recent years,

\footnotetext{
${ }^{29}$ Humphrey and Skvirskaja have indeed compared post-Soviet 'container markets' to nineteenth-century Russian trade fairs. See C. Humphrey and V. Skvirskaja, 'Trading Places: Post-Socialist Container Markets and the City', Focaal vol. 55, 2009, pp. 61-73.
} 
however, the Pamirs have also seen the development of economic and infrastructural projects that place great symbolic and economic emphasis on 'regional connectivity', notably China's 'Belt and Road' project and the 'China-Pakistan Economic Corridor'. Mostowlansky documents and analyses the 'oscillating' form of connectedness and disconnectedness between a small town in Tajikistan (Khorog) and a small town in northern Pakistan (Karimabad). The analytical motivation for exploring the 'ephemeral' forms of convivialityoften also 'marked by silence'-that intermittently connect these two towns is the shared sense among the inhabitants of having once belonged to a shared space. Mostowlansky aptly refers to this sense of the past as the "charging" of the past with the present and vice versa'. The shared region to which the inhabitants of these towns intermittently claim a sense of collective attachment cuts across Cold War boundaries, those of the present-day nation-states of Tajikistan, Pakistan, China, and Afghanistan, as well as imperial-era geopolitical boundaries between the Russian and British 'spheres of influence'. Life in this borderland has resulted in its peoples having complex, if not uneasy, relations with their superordinate political entities in the course of the past two centuries. For Mostowlansky, this informs the ways in which, in both Khorog and Karimabad, there is a sense of being at the epicentre of inter-Asian and even global connections, but simultaneously of experiencing marginalization from political power. Such tensions also powerfully inform the ways in which people in the two towns relate to a shared past in the absence of physically crossing the boundaries of the two nation-states in which they reside. On a general level, inhabitants of Khorog and Karimabad regard themselves as being bound by ties of culture and history but dissected by different types and degrees of modernity. While affiliation in both towns to the Ismai'li form of the Islamic tradition offers grounds for collective commitment to shared ethical principles across the space, these principles are often also geographically moored to the region in a manner that makes possible distinctions with further Ismai'li communities in the transnational realm. Past trajectories and future horizons of cross-border conviviality are evoked, then, in the context of a fragmentary present in which the nation-state lingers 'amidst local and transnational boundaries'. The complex infusion between past and present is further underscored by Mostowlanksy in his discussion of how one of the most likely sites for inhabitants from the two towns to physically interact today is in one of the region's former imperial centres: London. 


\section{Conclusion}

As a wide range of scholarship in recent years has shown, the processes through which moral relations, identities, and selves are fashioned in particular contexts involve the repeated and purposeful deployment of disciplining practices and modes of self-control that are pursued with the intention of achieving a particular definition of the good. ${ }^{30}$ In our understanding, the enactment of conviviality is not a carefree, thought-free, lackadaisical mode of sociality that effortlessly results in social, if shallow, forms of bonhomie. Nor is conviviality 'merely' performed for some narrowly instrumental end: to maximize profit, to avoid the costs of conflict, to keep a trade relationship going. Rather, the effort of conviviality is to be located not only in the repeated and sustained enactment of convivial ways of doing things, but also imaginatively in the continual and ongoing capacity and willingness to interpret such forms of behaviour in a frame that opens rather than closes the possible spaces for future interaction and engagement.

The articles contained in this collection reveal both this element of effort and the creative dynamism of this moment of reframing-in the decision to interpret an ethnic slur shouted at a market stall as 'friendly banter' rather than a source of offence, for instance, or in the reframing of an asymmetrical border encounter as an unforced act of hospitality. In this volume we have argued that marginal hubsprecisely because of their ephemerality, their indeterminacy, their lack of easy categorization-provide a privileged site for exploring such efforts ethnographically and for attending to the modes of framing through which informants reason about, and reflect upon, the circumstances of their (co)existence.

Beyond this empirical contribution, 'marginal hubs' pose a theoretical challenge to the burgeoning exploration of space, scale, and connectivity in the historical and anthropological study of modern Asia. Marginal hubs are places in which encounters with difference are a pervasive feature of daily life, yet such sites exist beyond the continent's celebrated urban centres. Indeed, marginal hubs do not fit easily into the conventional binaries through which social life has tended to be explored: urban versus rural, mountain versus lowland, inland versus oceanic, connected versus disconnected, within or beyond the gaze of the centralizing state. Perhaps as a result of the uneasy

\footnotetext{
${ }^{30}$ See, programmatically, S. Mahmood, Politics of Piety: The Islamic Revival and the Feminist Subject (Princeton: Princeton University Press, 2005).
} 
relationship of marginal hubs to conventional scales of analysis, they trouble the limits and boundaries of (sub-)continental thinking in a more explicit manner than is the case for more general models of Asian 'sites of interaction'. ${ }^{31}$ The case studies presented in this special issue call upon us to actively interrogate the very category of 'Asia' as a self-evident framework for enquiry. As Mostowlansky shows, for instance, it is precisely the awareness of living amid Cold War borders between South and Central Asia that fosters the particular modes of convivial sensibility and curiosity that inform the historical enquiries and 'scale-making projects' of his Pamiri interlocutors. Nor is that working out moored to any finite 'Asian' territory. As Nikolotov reveals, Moscow markets and peri-urban shashlyk gatherings can be paradigmatic sites for exploring inter-Asian modes of getting along among Vietnamese, Afghan, Uzbek, Tajik, and Kyrgyz traders, just as jiagongchang workshops in Guangzhou are critical nodes in the production of clothing destined for Australia. Indeed, ethnographic attention to marginal hubs of the kind that we attempt in this collection reveals the ways in which 'Asia' itself becomes part of the imaginative framework through which conviviality is negotiated, and by means of which claims to sameness and difference are reflected upon in the interstices of daily life.

${ }^{31}$ T. Harper and S. Amrith, 'Sites of Asian Interaction: An Introduction', Modern Asian Studies vol. 46, no. 2, 201 2, pp. 249-257. 